\title{
فاعلية التحكم بتكرار الحمل باستخدام تمارين مهارية في عدد من القدرات المهارية
}

\section{للاعبي الناشئين بكرة القدم}

$$
\text { أ.م.د. صادق جعفر محمود أمامعة ديالى - كلية التربية البلنية وعلوم الرياضة. شروق مهدي كاظم }
$$

ali925759@gmail.com

07716067745
Sadiq.football4@gmail.com

07700693394

\section{مستخلص البحث}

يهدف البحث الـى مدى فاعليـة التحكم بتكرار الحمل في عدد من القدرات المهاريـة للناشئين بكرة القدم • وقد استخدم الباحثان المنهج التجريبي لملاعمته لطبيعة البحث ,تكونت عينة البحث من لاعبي ناشئين نادي الجيش الرياضي بكرة القدم

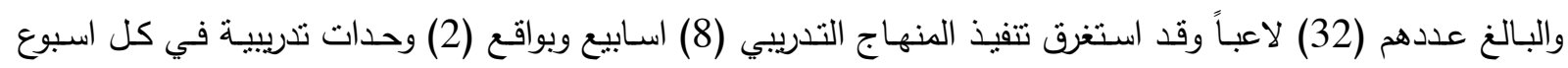

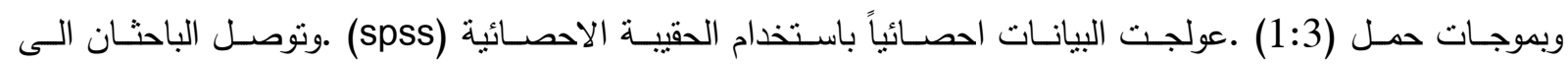
الاستتناجات الاتية :كانت فاعليـة التحكم بتكرار الحمل تاثيراً ايجابياً في تطوير عدد من القدرات المهاريـة المعتمدة في البحث كذلك كانت التمارين المهارية لها فاعلية ايجابياً في تطوير عدد من القدرات المهارية المعتمدة في البحث .ومن خلال ذلك اوصى الباحثان ضرورة استخدام اسلوب التحكم بتكرار الحمل في تطوير القدرات المهاربة بكرة القدم بالاضـافة الى استخدام قواعد التدريب الفتري منخفض الثدة عند تطوير القدرات المهارية بكرة القدم • الكلمات المفتاحية : التحكم بتكرار حمل - تمارين مهارية - قدرات مهارية - كرة القدم

\section{ABSTRACT \\ The Effect Of Load Frequency Control In Skill Exercises On Some Skill Abilities of Young Soccer Players}

\section{Asst .Prof .Sadeq Jaafar Mahmood Asst .Prof . Sherouq Mehdi College of Physical Education and Sports Sciences}

The research aimed at identifying the effect of load frequency control in a number of skill abilities of young soccer players. The researchers used the experimental method on (32) soccer player. The training program was applied for (8) weeks with (2) training sessions per week. The data was collected and treated using SPSS. The researchers concluded that controlling load frequency have a positive effect on developing many skill abilities as well as the positive effect of skill exercises on developing many skill abilities. Finally the researchers' concluded the necessity of using load frequency control to develop skill abilities in soccer.

Keywords : load frequency control, skill exercises, skill abilities, soccer. 
عملية التدريب في كرة القدم يجب ان تكون مبنية على اسس علمية سليمة وحديثة معتمدة على العلوم المهمة الغرض

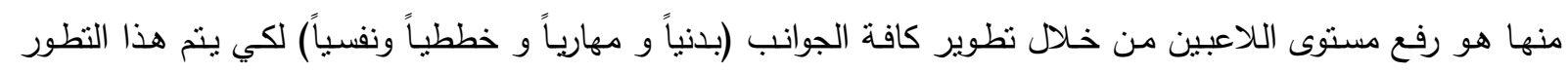
والجانب المهاري للاعبي كرة القدم له الاهية الكبيرة ,اذ يتم تطويره بالاعتماد على الطرق التدريبية والاساليب المختلفة

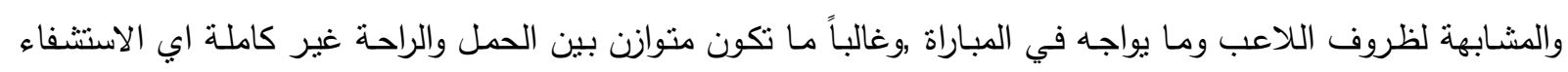
يكون غير كامل , وان اقرب هذه الطرق هو التدريب الفتري بنوعيه بالإضافة الى تقنين حمل التدريب (ثدة -حجم كراحة)

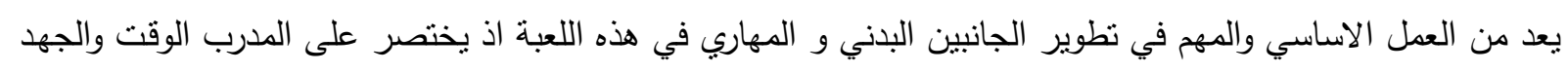

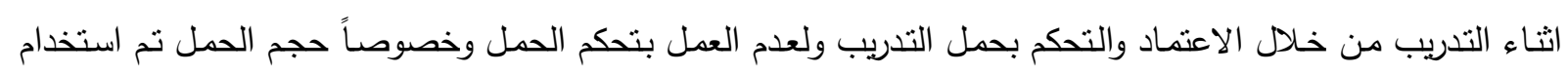

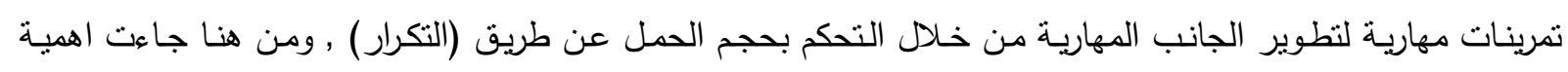
البحث في اعداد منهج تدريبي للتحكم بتكرار الحمل وفاعلية ذلك في عدد من القدرات المهارية للاعبي الناشئين بكرة القدم.

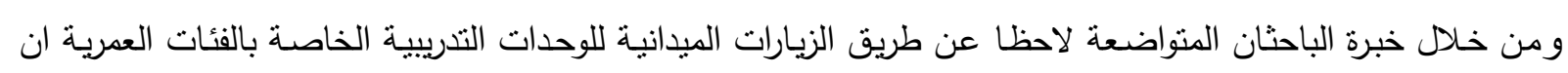

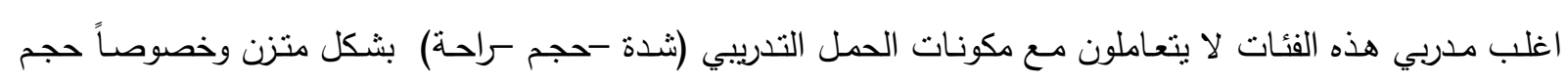

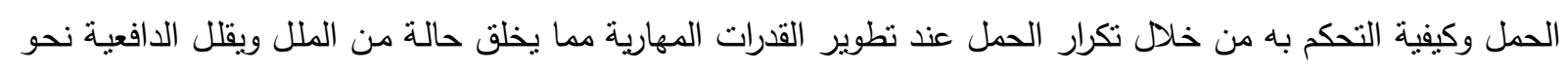

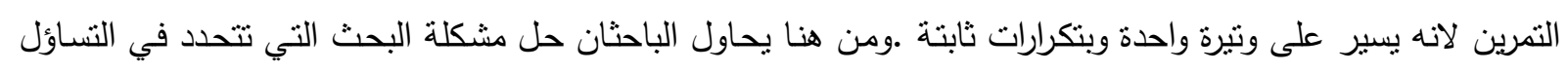

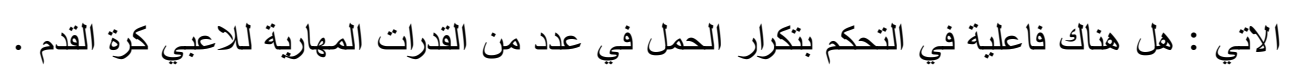

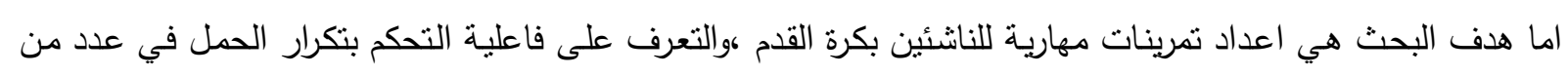

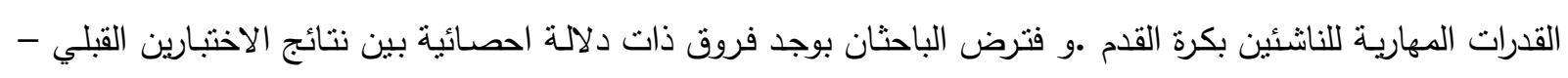

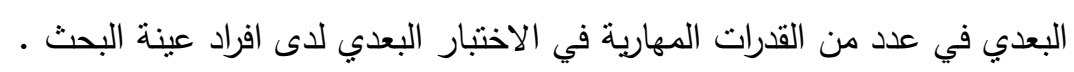
اثـارة دراسـة (القادر) "ان نخلق اثثاء التدريب ظروف قريبـة الى ظروفـا التتافس الفعلي اثتـاء المباراة".(القادر ،2014 175) ـ كنلك بينت دراسة (حمودي) "ان المناهج التنريبية بطريقة التدريب الفتري المنخفض الثدة تتيح للمدرب امكانية

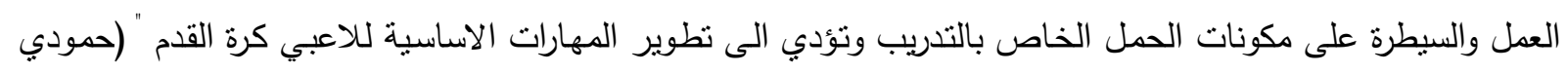

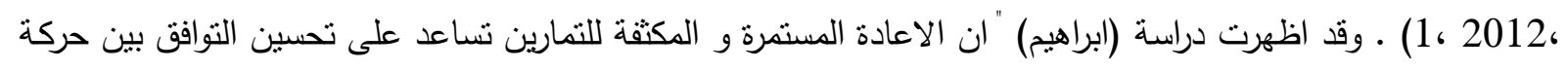

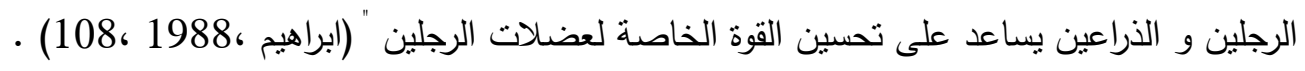

\section{الطريقة والادوات.}

استخدم الباحثان المنهج التجريبي لملاءمته وطبيعة البحث . وحدد الباحثان مجتمع البحث بالطريقة العدية وهم لاعبي

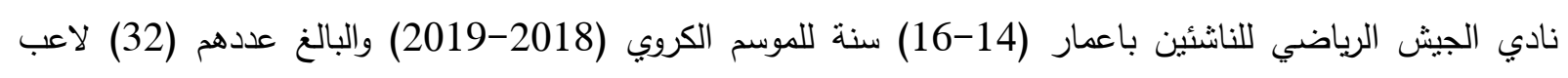

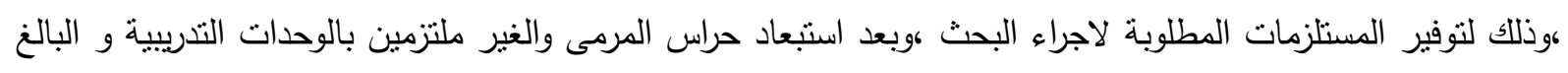

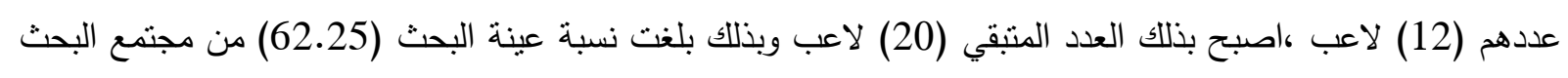
الاصلي . لغرض التأكد من التوزيع الاعتدالي لعينة البحث فقد عمد الباحثان الى استخدام قانون معامل الالتواء في

المتغيرات المبحوث وكما موضح في الجدول (1) ل 
الجدول (1): يبين التوزيع الاعتدالي لأفراد عينة البحث في عدد من القدرات المهارية بكرة القدم .

\begin{tabular}{|c|c|c|c|c|c|c|}
\hline قيمة معامل & الوسيط & الانحراف & الحسابي الحسط & القياس & عدد & اللهعالر الاحصائية \\
\hline-0.294 & 5 & 0.511 & 4.95 & درجة & 20 & دقة المناولة . \\
\hline-1.122 & 9 & 0.802 & 8.7 & درجة & 20 & دقة التهديف. \\
\hline 0.921 & 5 & 0.489 & 5.15 & درجة & 20 & التحكم بالكرة (الاخماد) . \\
\hline-0.585 & 22.37 & 0.364 & 22.31 & ثانية & 20 & الاحرجة . \\
\hline
\end{tabular}

ومن خلال النظر الى الجدول (1) يتضح ان قيمة معامل الالتواء كانت بين (3د) وبذللك فان العينة تتوزع توزيعاً

اعتدالياً.

الاختبارات المهارية المستخدمة بالبحث:

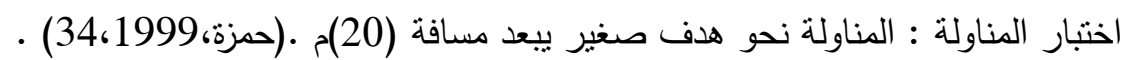

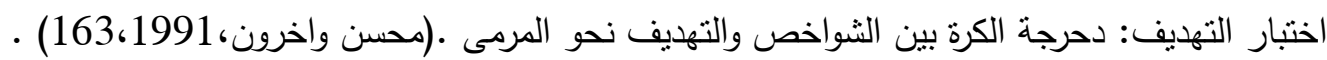

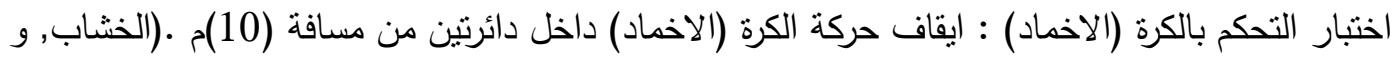

نون، (85-84،2005).

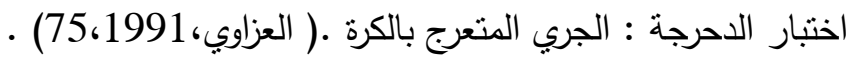

وتم استخدام التصميم التجريبي باسلوب المجموعة الواحدة ذات الاختبارين القبلي - البعدي انسجاما لطبيعة المشكلة .

و قام الباحثان بعد تحليل محتوى الدراسات والمصادر العلمية بتصميم برنامج تدريبي قائم على اسس علمية وتم عرضه على بعض السادة المختصين في مجال علم التدريب الرياضي وكرة القدم وتم الحصول على الملاحظات الخاصة بالبرنامج

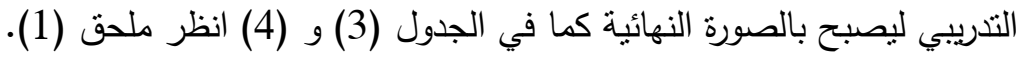

وتم بدء كافة الوحدات التدريبية بالاحماء العام من اجل تهيئة جميع عضلات الجسم ،ثم القيام باجراء الاحماء

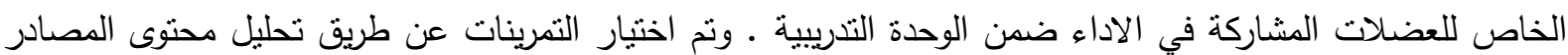

العلمية وعن طريق المقابلة الثخصية للخبراء ذوي الاختصاص ،والتي سنطبق في القسم الرئيسي انظر ملحق (2) ـ وتكون البرنامج التدريبي للمجموعة التجريبية من (8) اسابيع وبواقع دورتين متوسطنين و وحدتين تدريبيتين في الدورة

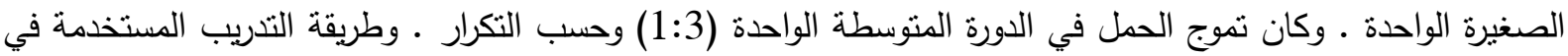

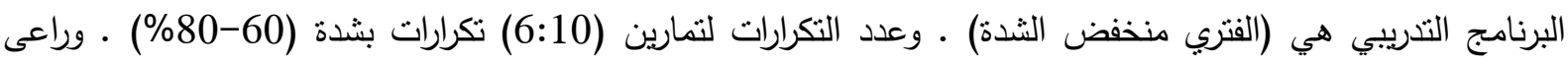
الباحثان ان يكون في كل وحدة تمرينات لمهارة المناولة و التحكم بالكرة (الاخماد) والتهديف و الدحرجة) وتم اداء الوحدات التدريبية خلال الايام (الاحد ،الثلاثاء) اذ تتفذ المجموعة التجريبية (24) وحدة تدريبية. وتم التحكم بدرجة الحمل بالاعتماد على التغير في التكرار • وتم تحديد فترات الراحة بين التكرارات عن طريق التجربة الاسنطلاعية وتحليل محتوى المصادر

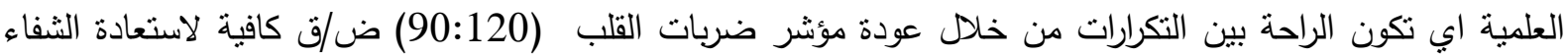
للاعبين وتكون الراحة بين تمرين واخر (3) دقيقة راحة غير كاملة .وكان مؤثر النبض دور مهم في التوصل الى الراحة بين التكرارات. وان تموج درجة الحمل للتمارين كان معتمدا على التحكم بدرجة الحمل التدريبي عن طريق التكرار • وتم اجراء ثلاث تجارب استطلاعية على (5) لاعبين من مجتمع البحث: • التجربة الاستطلاعية الاولى : كانت بتاريخ( 2018/10/26) لمعرفة مدى امكانية تتفيذ وتطبيق الاختبارات المهارية وتجاوز الصعوبات والمشاكل التي تواجههم • 
• التجربة الاسنطلاعية الثانية : تم تتفيذها بتاريخ (2018/11/1) وكان الهدف منها التعرف على التمارين وامكانية تتفيذها في الوحدات التدريبية بشكلها النهائي والتعرف على مدى الراحة بين التكرارات والبين تمرين واخر • التجربة الاستطلاعية الثالثة : تم تتفيذها بتاريخ (2018/11/5) وكان الهدف منها التحكم بحجم الحمل عن طريق التكرارات وملائكتها داخل البرنامج التدريبي . نم اجراء الاختبار القبلي من تاريخ (2018/11/9). وتم البدء بتتفيذ البرنامج التدريبي بتاريخ (2018/11/11) ولغاية (2019/1/8) اذ طبقت المجموعة التجريبية (التمرينات المعد من قبل الباحثان ) ، وبواقع (2) وحدات تدريبية في الدورة الصغيرة الواحدة ولمدة (8) اساييع اذ قسمت على دورتين متوسطنين ،وعليه تم تتفيذ (24) وحدة تدريبية ونفذ هذا البرنامج في الجزء الرئيس من الوحدة التدريية وفي مرحلة الاعداد الخاص. في حين تتفيذ الاختبارات البعدية ابتداءً من (2019/1/10) بنفس الاجراءات والظروف والمتطلبات التي نم فيها تتفيذ الاختبارات القبلية. وتم استخدام الحقيبة الاحصائية (spss) في المعالجات الاحصائية . الجدول (2) : الاوساط الحسابية للفروق وقيمة (t) المحسوبة ودلالة الفروق بين الاختبارين القبلي - البعدي لمتغير البحث

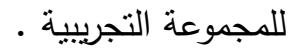

\begin{tabular}{|c|c|c|c|c|c|c|c|c|}
\hline \multirow{2}{*}{ الفروق } & \multirow{2}{*}{$\begin{array}{l}\text { قيمة } \\
\text { (sig) }\end{array}$} & \multirow{2}{*}{ 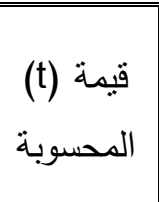 } & \multicolumn{2}{|c|}{ بعدي } & \multicolumn{2}{|c|}{ قبلي } & \multirow{2}{*}{ القياس } & \multirow{2}{*}{ لالاحصائية } \\
\hline & & & $\varepsilon^{ \pm}$ & س - & $\varepsilon^{ \pm}$ & س - & & \\
\hline معنوي & 0.000 & -42.13 & 0.745 & 7.85 & 0.511 & 4.95 & درجة & دقة المناولة \\
\hline معنوي & 0.000 & -46.99 & 0.825 & 12.55 & 0.801 & 8.70 & درجة & دقة التهديف \\
\hline معنوي & 0.000 & -22.65 & 0.598 & 7.40 & 0.489 & 5.15 & درجة & الاخماد \\
\hline معنوي & 0.000 & 33.05 & 0.393 & 21.25 & 0.364 & 22.30 & ثانية & الدحرجة \\
\hline
\end{tabular}

من خلال ملاحظتنا للجدول (2) يتنين لنا ان النتائج دلت على ما يأتي: وجود فروق ذات دلالة معنوية بين متوسطين

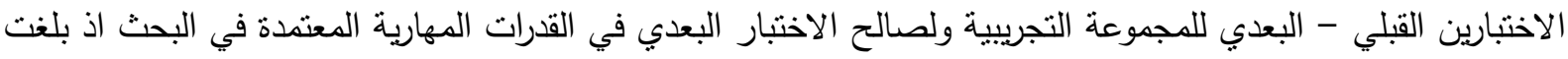
قيمة (sig) مقدارها (0.000) وهي اقل من حدود النقة البالغة (0.05) عند درجة حرية (19) •

المناقشة:

من خلال الجدول (2) يتبين وجود تطور معنوي لأفراد عينة البحث في كافة القدرات المهارية المعتمدة بالبحث وهي : (المناولة ,التهديف ,الاخماد, الدحرجة) عند المقارنة بين الاختبارين القبلي - البعدي لأفراد عينة البحث ,وهو يدل لإل على سلامة وصحة الاسس العلمية في تقنين الحمل التدريبي باتباع كافة المبادئ العلمية والميدانية في تدريب لاعبي ناشئة نادي الجيش الرياضي بكرة القدم بطريقة التدريب الفتري متخفض الثدة في الوحدات التدريبية كافة اذ "التخطيط والتنظيم والاستمرار على اسس علمية ,مما يضمن مستوى الحمل التدريبي والتوقيت الصحيح لنكراره" (طه رو اخرون،1989، 172). ويعزو الباحثان النطور المعنوي لافراد عينة البحث هو عملية التدرج في زيادة الحمل التدريبي في منهج البحث راذ الزيادة في الحمل التتريبي للتمارين المهارية كانت بصورة منتظمة ومناسبة لافراد عينة البحث من خلال الزيادة في تكرار درجة الحمل من دورة اسبوعية الى اخرى ومن دورة منوسطة الى دورة اخرى ومن ثم تحقيق التطور المطلوب ,اي ان مبدا التدرج في الحمل التدريبي يساهم وبشكل فعال في نجاح المناهج التدريبي .فلا بد من زيادة الحمل التدريبي بصورة تدريجية 
عن طريق التحكم بمكونات الحمل ومنها تكرار الحمل التدريبي. وكذلك يعزو الباحثان التطور لافراد عينة البحث الى انه تم

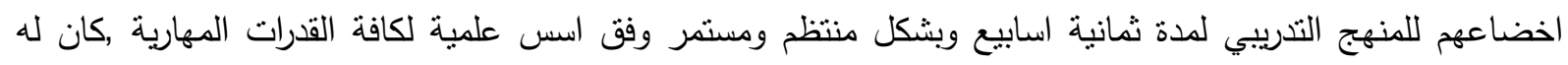
الدور الفعال وهذا ما اكده (سلامة) انه "عنما نتدرب لاسابيع بانتظام يحدث التكيف الفسلجي لهذا الجهد وهو ما يعمل على ولى تحسين قدرات اللاعب البدنية والوظيفية ,وكذلك تحسين من الفاعلية والقدرة على تحمل الاداء ومختلف النواحي الفنية المرتبطة بالنشاط التخصصي" (سلامة،2000،28) ـ بالاضافة الى وضع التكرارات المناسبة والراحة بينهما ساهمة في ولي ولئ عملية التكيف وهذا ما اتفق عليه (البساطي) "فقد اثتتت التمارين العلمية لبحوث الكيمياء الحيوية زيادة مصادر الطاقة عند

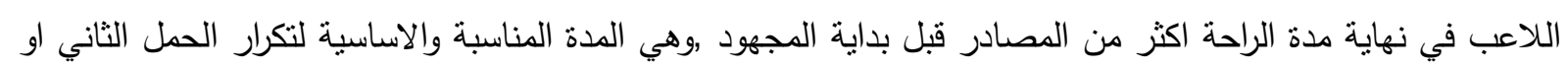

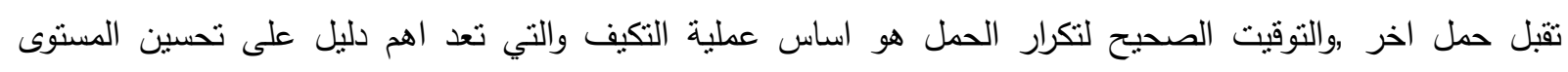

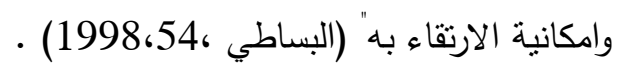

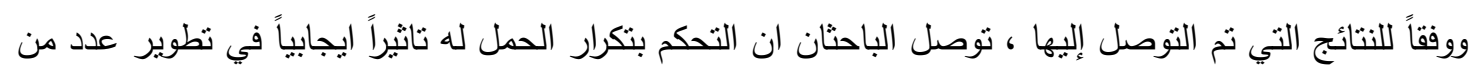

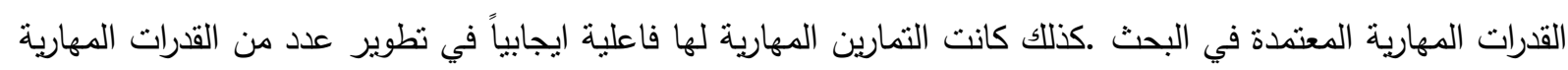

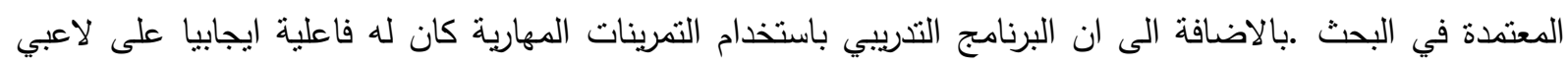

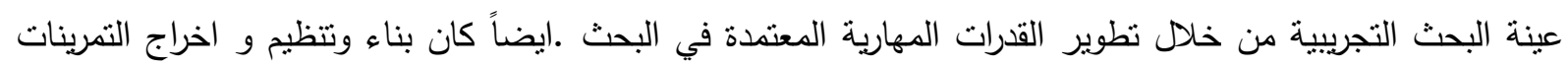
تأثنير نفسي على العينة وساهمة في فاعلية ورغبة اللاعبين . ومن خلال ذلك يوصي الباحثان باستخدام اسلوب التحكم بتكرار الحمل في تطوير القدرات المهارية بكرة القدم و

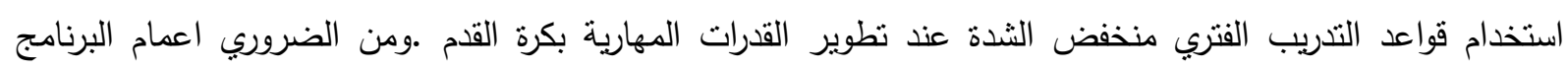

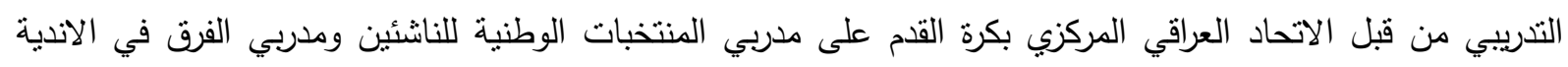

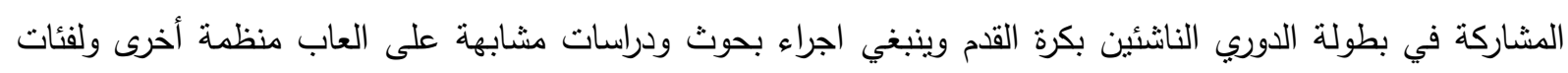
عمرية مختلفة.

\section{المصادر}

• ابراهيم محمد رضا ،واخرون (1988) .تاثير تمرينات القفز العميق على القفز العمودي للاعبي كرة السلة في الارجة

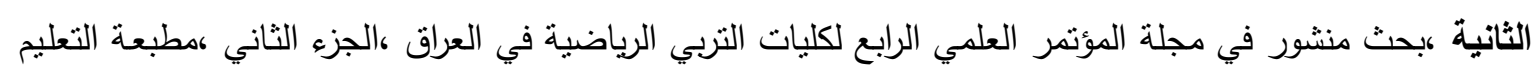

• اسماعيل طه ,و اخرون (1989) .كرة القدم بين النظرية والتطبيق ,دار الفكر العربي ,القاهرة . • امر اله احمد البساطي (1998) .اسس وقواعد التدريب الرياضي وتطبيقاته ,كلية التربية الرياضية رجامعة الاسكندرية • بهاء الدين ابراهيم سلامة (2000) .فسيلوجيا الرياضة والاداء البدني (لاكتات الدم) : ,ط : دار الفكر العربي للنشر ثامر محسن (واخرون) (1991) ـالاختبار والتحليل بكرة القدم , الموصل ،مطبعة جامعة الموصل

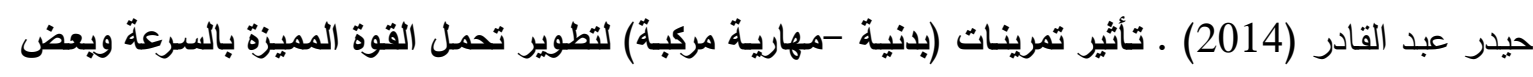

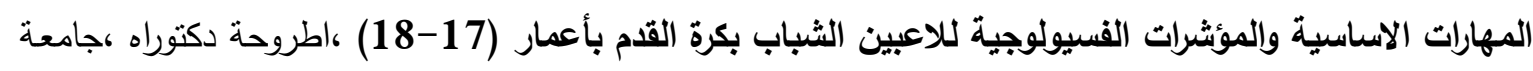
بغداد ،كلية التربية البدنية وعلوم الرياضية. • رعد حسين حمزة (1999) .اثر استخدام وسيلة المناطق المحدد في تنميـة المهارات الاساسية بكرة القدم, رسالة التئة ماجستير ,غير منشورة ركلية التربية الرياضية رجامعة بغداد . 

• زهير قاسم الخشاب , و معتز يونس ذنون (2005 ) مكرة القدم - مهارات - اختبارات - قانون , دار ابن الهيثم

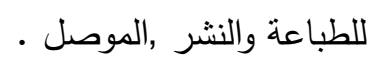
• زهير قاسم حمودي ،و محمود حمدون يونس (2012) .اثر تمارين بدنية مهارية باستخدام زمن المطاولية الخاصة في

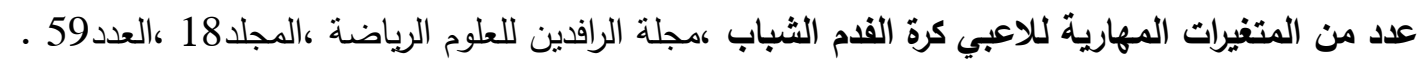

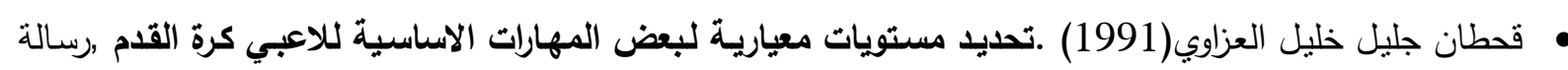
ماجستير ،جامعة بغداد ،كلية التربية الرياضية .

\section{الملاحق}

ملحق (1) :البرنامج التدريبي المقترح الجدول (3) يبين : ( الدورة المتوسطة الاولى )

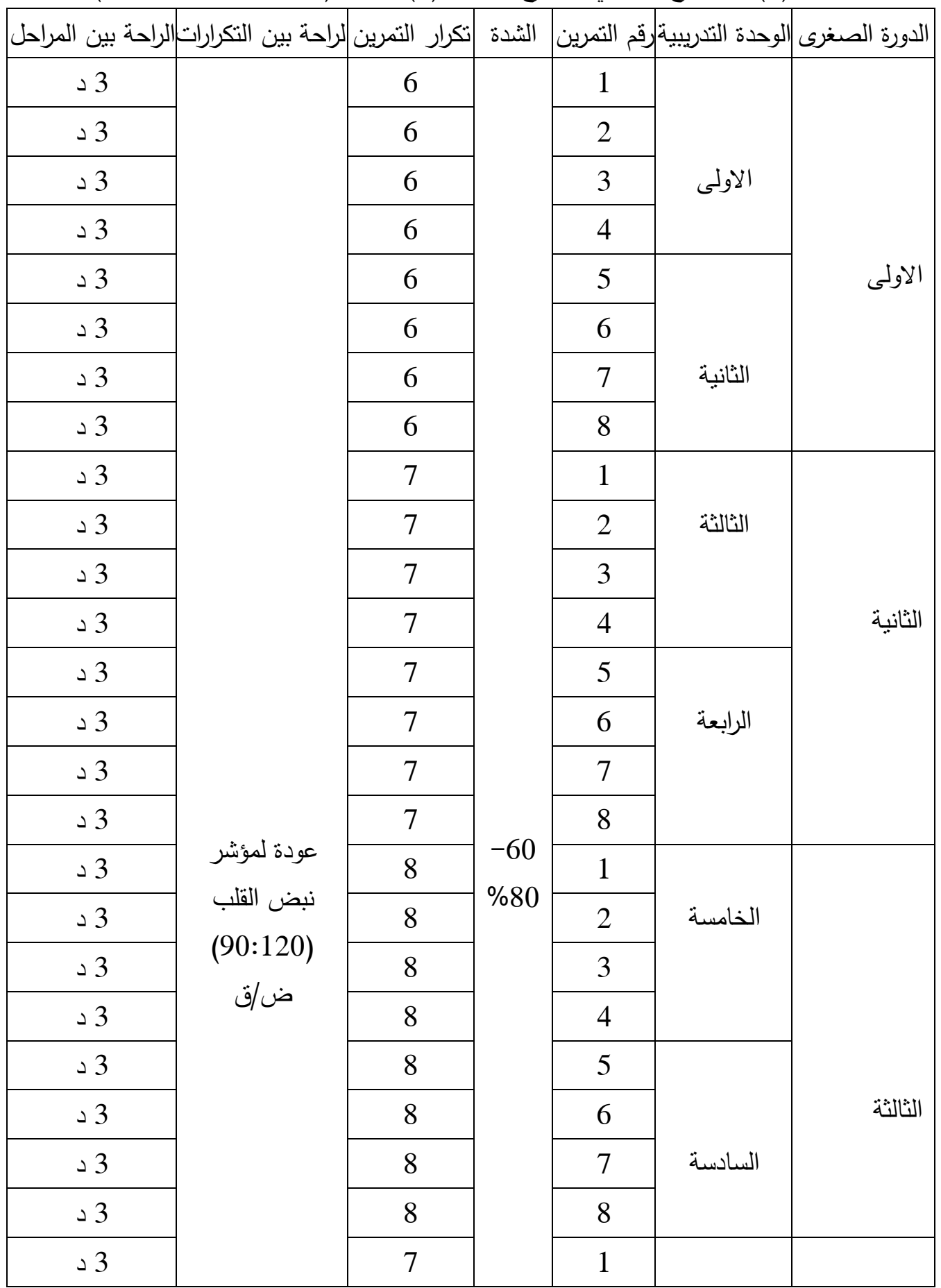


مجلة كلية التربية الرياضية / جامعة بغداد ** المجلد الحادي والثلاثون** العدد الثانى * 2019.

\begin{tabular}{|c|c|c|c|c|}
\hline 3 & 7 & 2 & \multirow[t]{3}{*}{ السابعة } & \multirow{7}{*}{ الرابعة } \\
\hline 3 & 7 & 3 & & \\
\hline 3 & 7 & 4 & & \\
\hline 3 & 7 & 5 & \multirow{4}{*}{ الثامنة } & \\
\hline 3 & 7 & 6 & & \\
\hline 3 & 7 & 7 & & \\
\hline 3 & 7 & 8 & & \\
\hline
\end{tabular}

الجدول (4) يبين : ( الدورة المتوسطة الثانية )

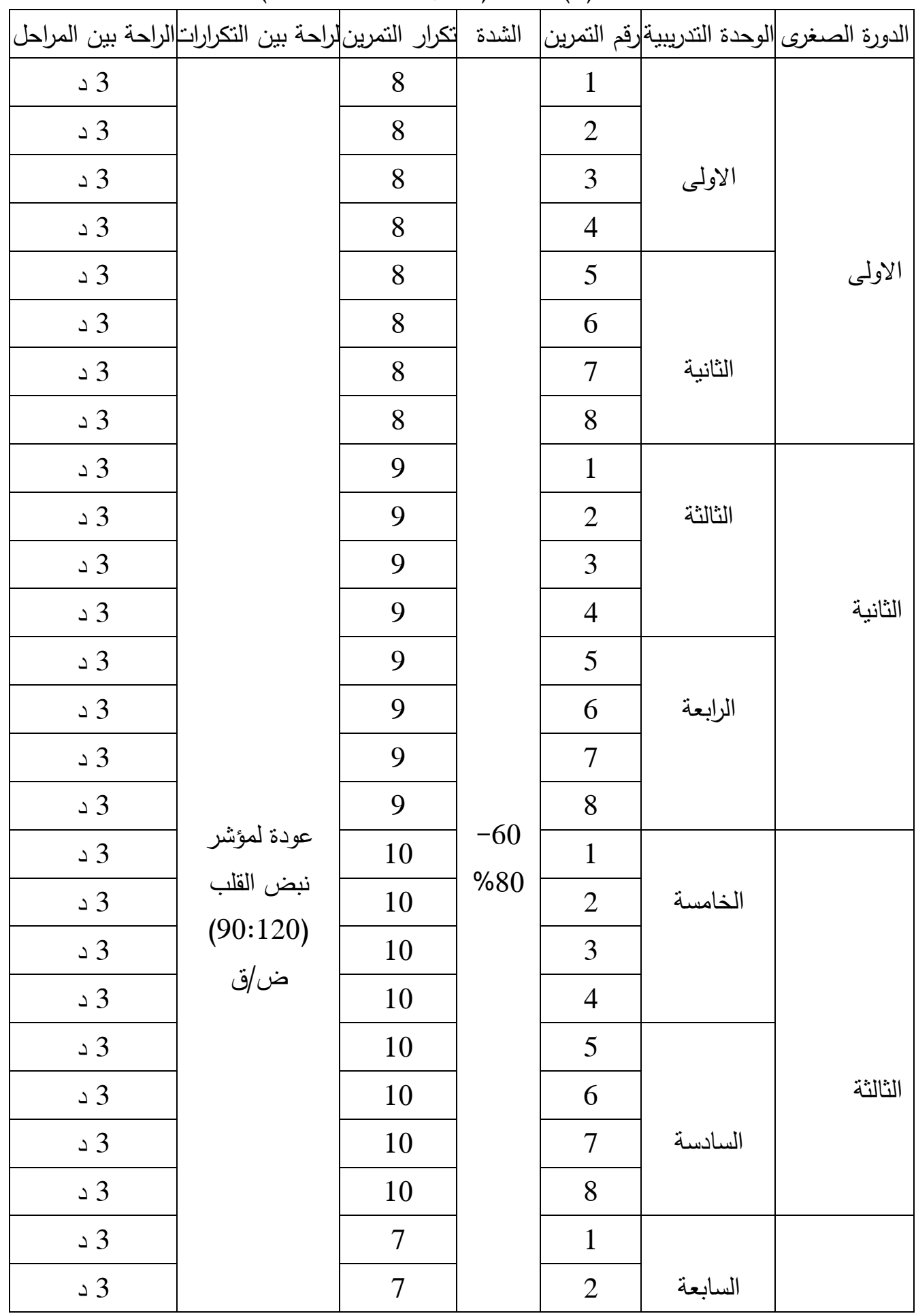




\begin{tabular}{|c|c|c|c|c|}
\hline 3 & 7 & 3 & & \multirow{6}{*}{ الرابعة } \\
\hline 3 & 7 & 4 & & \\
\hline 3 & 7 & 5 & \multirow{4}{*}{ الثامنة } & \\
\hline 3 & 7 & 6 & & \\
\hline 3 & 7 & 7 & & \\
\hline 3 & 7 & 8 & & \\
\hline
\end{tabular}

\section{ملحق (2) :التمارين المستخدمة في البرنامج التدريبي :}

• تمرين (1) : يهدف لنطوير المناولة اذ يتبادل كل لاعبين اثثين الكرة من بين (3) اهداف صغيرة التي توضع بينهم مـع تتويع اثكال التمرير المستقيم ثم القوسي ثم بوجه القدم وبجانب القدم وبداخل القدم شرط ان يكون التمرير نوعي وبوزن • مناسب لنوع التمرير

• تمرين (2) : يهدف لتطوير المناولة اذ يتبادل كل لاعبين الكرة عبر مسافة (5)م شرط ان يلعب المستلم الكرة بلمسـة واحدة الكرة للجهة الاخرى ومن ثم اعادة تمريرها للاعب المقابل فتحرك الكرة بعيداً عن جهة الاستلام تعني تحريكها

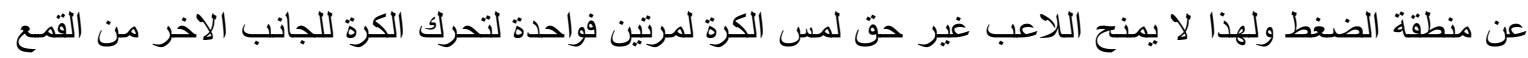
والثانية لتمرير الكرة للاعب المقابل لينفذ التمرين بعدة مجاميع • • تمرين (3) : يهدف لتطوير الاخماد لدى كل لاعب كرة .يبدأ اللاعب رقم (1) بركل الكرة بخفة بيدا زميله الموجود

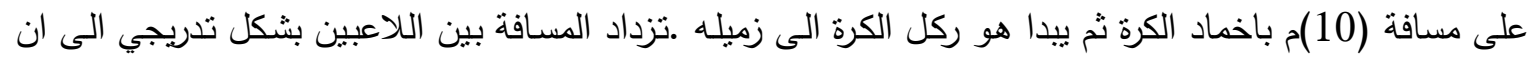

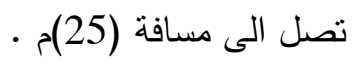

• تمرين (4) : يهدف لتطوير الاخماد حالما ينطلق اللاعب الى الامام يبدا المدرب بمناولته كرة ارضية اذ يبدا اللاعب

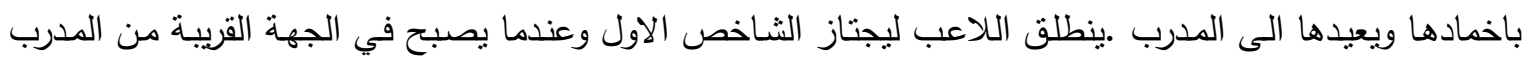

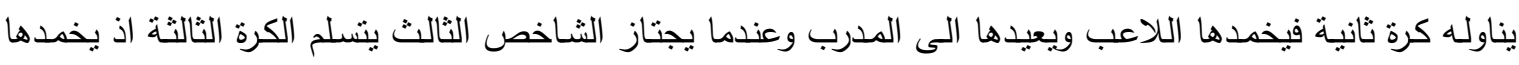

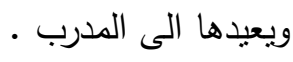

• تمرين (5) : يهدف لنطوير الدحرجة اذ يحدد مربع صغير وسط الدائرة ليتوزع عليها اللاعبين مع كرة واحدة مع لاعب واحد فقط (لاعب الكرة) الذي ينفذ الدحرجة باتجاه المربع الصغير وعند الدخول فيه يعمل اللاعب على تغير اتجاه

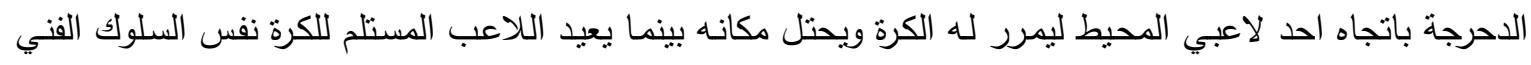

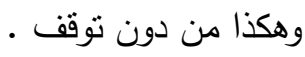
• تمرين (6) : يهدف لتطوير الدحرجـة اذ ينفذ اول لاعب من كل مجموعـة الدحرجة باتجاه القـع الذي يقابله وتغيير الاتجاه قربه ثم تمرير الكرة للاعب الذي يقف في اول المجموعة المقابلة و الانتقال خلف تلك المجموعة . • تمرين (7) : يهدف لتطوير التهديف يقف اللاعب امام علامة الجزاء الذي يبعد عنها (10) متر الكرة اسفل قدم الرجل يبدا بدحرجة الكرة الى جانب علامة الجزاء .يتظاهر بانه سينطلق باتجاه علامة الجزاء وفعلاً يعمل ذللك ولكن لخطوة

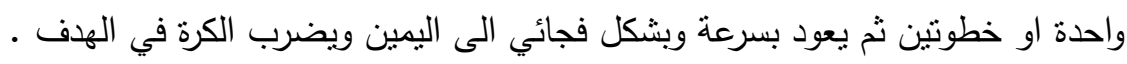

ين (8) : يهدف لتطوير التهديف اذ يتمركز اللاعب داخل مربع محدد امام الهدف بوجود ثلاث لاعبين مجهزين

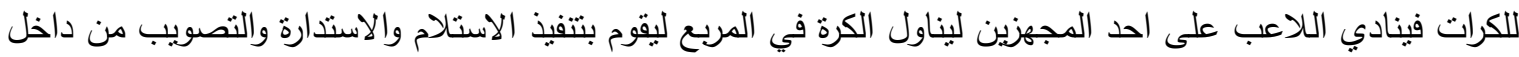
المربع وحالة الانتهاء يستدير للمناداة على الكرة الثانية لتنفيذ نفس العمل وهكذا مـع الكرة الثالثة على شرط ان يكون التهديف من المربع الذي يبعد على (10)م عن الهدف ومن المهم العمل بعدة مجاميع على عدة اهداف وبنفس 